See discussions, stats, and author profiles for this publication at: http://www.researchgate.net/publication/280078549

\title{
Dermoscopy of clonal seborrheic keratosis
}

ARTICLE in JOURNAL OF THE AMERICAN ACADEMY OF DERMATOLOGY · AUGUST 2015

Impact Factor: 5 · DOI: 10.1016/j.jaad.2015.04.013

3 AUTHORS, INCLUDING:

Salvador J Diaz-Cano

King's College London

234 PUBLICATIONS $\mathbf{1 , 7 0 0}$ CITATIONS

SEE PROFILE 


\title{
Dermoscopy of clonal seborrheic keratosis
}

\author{
Sheena Ramyead, MBBS, BSC, ${ }^{\mathrm{a}}$ Salvador J. Diaz-Cano, MD, PhD, ${ }^{\mathrm{b}}$ and Lucia Pozo-Garcia, MD, PhD ${ }^{\mathrm{a}}$ \\ London, United Kingdom
}

Key words: clonal; dermoscopy; keratosis; seborrheic.

\section{CLINICAL PRESENTATION}

A 28-year-old woman presented with a long history of a mole on her leg that had been changing in shape and size over the previous few months. There was no personal or family history of skin malignancy.

On examination, there was a reddish well-circumscribed plaque on the side of her left thigh (Fig 1).

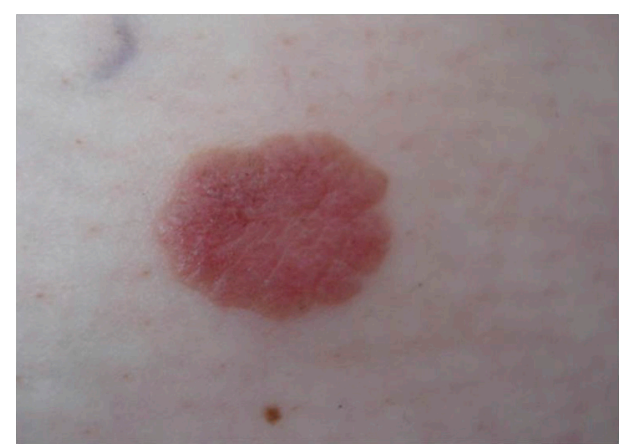

Fig 1. Clonal seborrheic keratosis. Well-circumscribed reddish patch with slightly scaly surface.

\section{DERMOSCOPIC APPEARANCE}

Dermoscopy showed diffuse pinkish background, white network, and multiple vessels (glomerular, linear-irregular, and dotted vessels) (Figs 2 and 3).

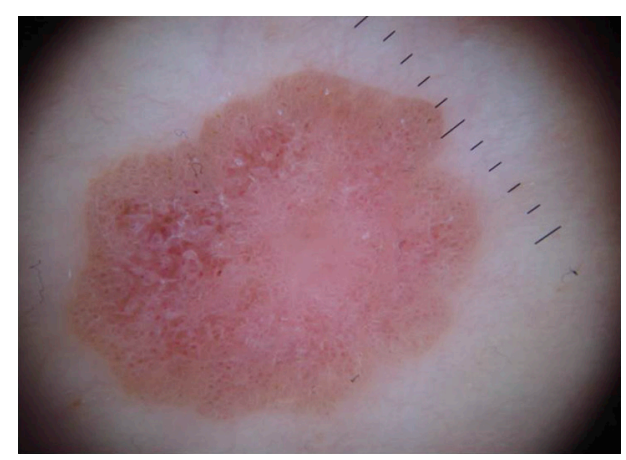

Fig 2. Clonal seborrheic keratosis. Dermoscopy shows a vascularized lesion with diffuse pinkish background, white network, and multiple vessels.

$\overline{\text { From Homerton University Hospital }^{\mathrm{a}} \text { and Kings College Hospital. }}{ }^{\mathrm{b}}$ Funding sources: None.

Conflicts of interest: None declared.

Reprint requests: Lucia Pozo-Garcia, MD, PhD, Department of Dermatology, Homerton University Hospital, Homerton Row,

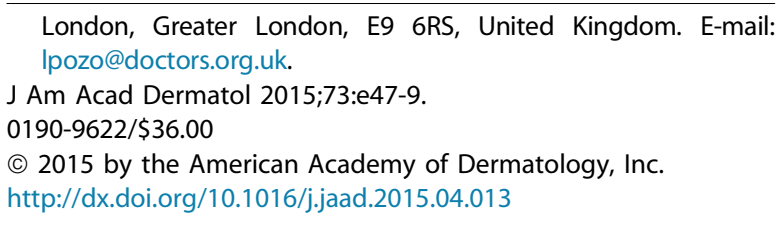




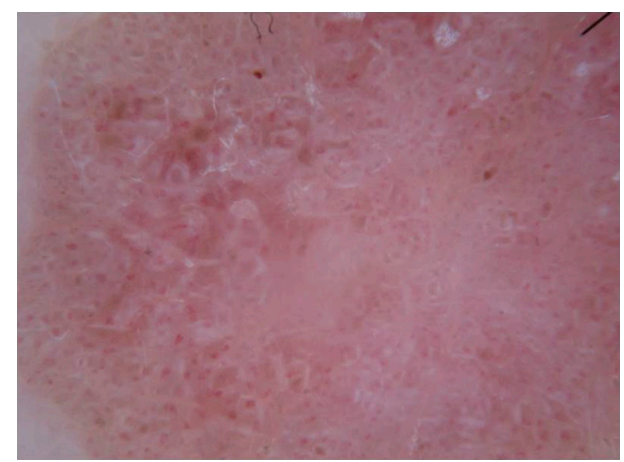

Fig 3. Clonal seborrheic keratosis. Close-up view highlighting the presence of glomerular, hairpin, and dotted vessels.

\section{HISTOLOGIC DIAGNOSIS}

Histology revealed an intraepidermal proliferation of basaloid keratinocytes without atypia in a nested growth pattern, along with hyperkeratosis, parakeratosis, and superficial lobulated blood vessels (Fig 4).

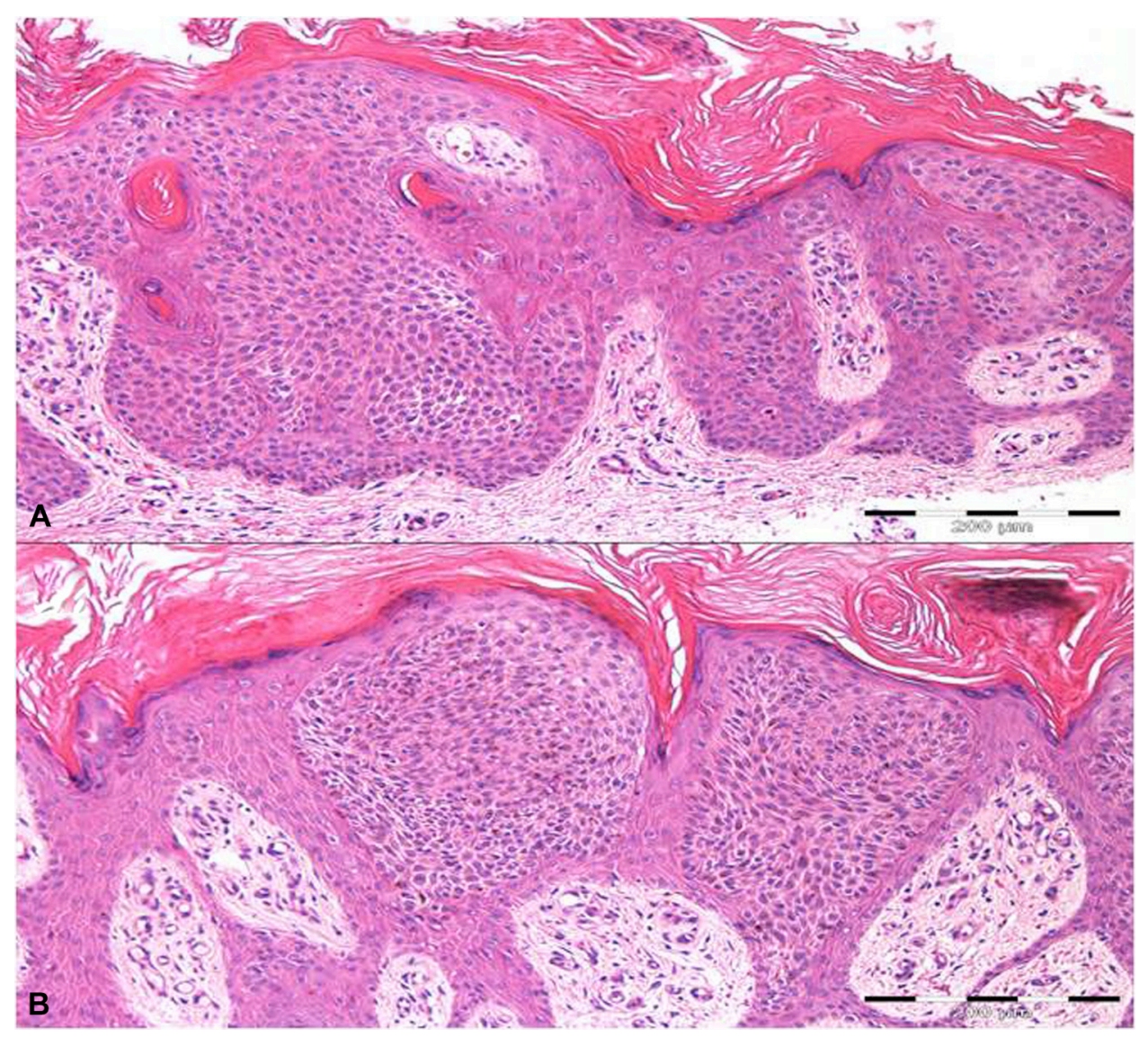

Fig 4. Clonal seborrheic keratosis. Histology shows a clonal seborrheic keratosis. 


\section{KEY MESSAGES}

Clonal seborrheic keratoses are uncommon, are usually pigmented, and cannot be clinically differentiated from ordinary seborrheic keratoses. The histologic hallmark is the presence of sharply demarcated intraepithelial nests of basaloid cells (Borst-Jadassohn phenomenon). Although dermoscopy is a helpful diagnostic tool for atypical seborrheic keratoses, the clonal variant may represent a dermoscopic pitfall. ${ }^{1}$ Clonal seborrheic keratoses present with bluebrown globules and milia-like cysts on dermoscopy, ${ }^{2}$ but vascular structures have not been described to our knowledge.

We present an unusual acquired red patch in a young patient, showing polymorphic vessels on a diffuse pink and whitish background with white network. Polymorphic vessels on dermoscopy suggest malignancy, as they may appear in squamous cell carcinomas, Spitz nevi, and melanomas. Clonal seborrheic keratoses may present as nonpigmented patches and should be considered in the differential diagnosis of acquired erythematous vascularized lesions. Biopsy is mandatory to confirm the diagnosis.

\section{REFERENCES}

1. Zalaudek I, Ferrara G, Argenziano G. Clonal seborrheic keratosis: a dermoscopic pitfall. Arch Dermatol. 2004;140(9):1169-1170.

2. Longo C, Zalaudek I, Moscarella E, et al. Clonal seborrheic keratosis: dermoscopic and confocal microscopy characterization. J Eur Acad Dermatol Venereol. 2014;28:1397-1400. 